\title{
IDEIAS E DISCURSOS SOBRE A JUSTIÇA DO TRABALHO NO BRASIL: SUA INCLUSÃO NO PODER JUDICIÁRIO EXAMINADA A PARTIR DA ASSEMBLEIA CONSTITUINTE DE 1946
}

\section{Ricardo Lourenço Filho}

\section{Resumo}

A implementação no Brasil de uma Justiça do Trabalho de feição corporativa foi combatida por correntes liberais, mas defendida pelos apoiadores do autoritarismo estatal de Getúlio Vargas. Esse confronto de ideias é explicitado no debate entre Oliveira Viana e Waldemar Ferreira, na segunda metade da década de 1930. O objetivo deste artigo é investigar essa etapa do processo de consolidação da Justiça do Trabalho, que vai culminar na sua inclusão no Poder Judiciário. Para tanto, é analisado, num primeiro momento, o debate entre Oliveira Viana e Waldemar Ferreira acerca da Justiça do Trabalho e de sua competência, em especial a normativa. Em seguida, a partir dos Diários do Poder Legislativo, são examinados os discursos proferidos na Assembleia Constituinte de 1946, relativos à Justiça do Trabalho e à sua incorporação no Poder Judiciário. Os resultados da pesquisa indicam que a oposição liberal cedeu lugar ao reconhecimento da função da Justiça do Trabalho e do direito do trabalho como instrumentos necessários ao tratamento dos conflitos entre empregados e empregadores. Essa constatação leva à indagação, para estudos futuros, sobre como a Justiça do Trabalho vem efetivamente realizando essa função.

Palavras-chave: História do direito. Justiça do Trabalho. Oliveira Viana. Assembleia Constituinte de 1946. Constituição de 1946. 


\section{INTRODUÇÃO}

A Justiça do Trabalho foi instituída, no Brasil, ainda no primeiro governo de Getúlio Vargas, como uma justiça administrativa, desvinculada do Poder Judiciário e subordinada ao Poder Executivo, por meio do Ministério do Trabalho. A Constituição de 1946 modificou esse aspecto, incorporando a Justiça Trabalhista no Poder Judiciário. Em seus Comentários, Pontes de Miranda (1963, p. 420) afirma que a Constituição de 1946 corresponde ao terceiro momento da Justiça do Trabalho, em que há sua estatização, isto é, seu ingresso como parte de um dos três poderes do Estado. Para o autor, "as consequências jurídicas" desse fato são significativas:

o juiz do Tribunal Superior do Trabalho e o juiz dos Tribunais Regionais do Trabalho são juízes, no sentido em que o são os juízes do Tribunal Superior Eleitoral e dos Tribunais Regionais Eleitorais; e a lei pode mesmo fazê-los idênticos, como juízes, aos juízes dos Tribunais Federais de Recursos (grifos no original).2

Além disso, segundo Pontes de Miranda (1963, p. 422), seria resolvida de vez a discussão sobre a natureza das decisões proferidas pela Justiça do Trabalho, confirmando-se o posicionamento anterior do Supremo Tribunal Federal, no sentido de que a Justiça Trabalhista correspondia a uma instância jurisdicional, e não administrativa (de maneira que não seria cabível a revisão de suas decisões pela Justiça Comum). ${ }^{3}$

A despeito da importância conferida por Pontes de Miranda, é interessante observar que os próprios magistrados trabalhistas não atribuem maior relevo ao fato da incorporação da Justiça do Trabalho no Poder Judiciário.

Angela de Castro Gomes (2006, p. 60), propondo uma reflexão sobre a história dessa Justiça a partir da perspectiva dos magistrados trabalhistas, identifica um primeiro "tempo" no passado da Justiça do Trabalho, o qual abrange um período de mais de 40 anos. Esse "tempo" é associado a uma tradição, arraigada em especial no Poder Judiciário, de desprestígio ao direito do trabalho, encarado como um "direito menor".

A partir das entrevistas realizadas com os magistrados, Angela de Castro Gomes (2006, p. 62) observa que o ingresso da Justiça do Trabalho no Poder Judiciário "foi um fato praticamente esquecido nos depoimentos, talvez porque tenha sido inócuo para atingir a tradição de desprestígio que já se havia formado e instalado nos

\footnotetext{
${ }^{1}$ Doutor em Direito, Estado e Constituição pela Universidade de Brasília. Professor de graduação e pós-graduação em Direito no Instituto Brasiliense de Direito Público. E-mail: ricardo.lourencofilho@gmail.com

${ }^{2}$ A Constituição de 1946, em seu art. 122, reservava à legislação ordinária a instituição dos Tribunais Regionais do Trabalho e das Juntas de Conciliação, bem como a constituição, investidura, jurisdição, competência, garantias e condições de exercício dos órgãos da Justiça do Trabalho (BRASIL, 1946).

${ }^{3}$ É representativa a decisão do Supremo Tribunal Federal no Recurso Extraordinário no 6.310, julgado em 13 de julho de 1943, sendo relator o Min. Goulart de Oliveira (BRASIL, s/d, p. 149).
} 
meios jurídicos em geral". ${ }^{4}$

Pergunta-se, então, o que estaria por trás da alteração realizada pela Constituição de 1946. Ou, de outra forma: a análise sobre essa modificação pode revelar algo a respeito da história da Justiça do Trabalho e do direito do trabalho no Brasil? E, em caso positivo, o quê?

O presente texto procura desenvolver o argumento de que a modificação promovida pela Constituição de 1946 diz algo mais, e num sentido que vai além do indicado por Pontes de Miranda. É significativo que uma instituição como a Justiça do Trabalho, cuja implementação encontrara relevante oposição por parte de correntes liberais, dada sua feição corporativa, tenha sido não apenas mantida com sua estrutura e competência, mas, além disso, reforçada, em termos de independência e autonomia, pela Constituição de 1946. Essa última, aliás, apresentava, numa certa abordagem, a característica de assegurar "um Estado social de direito vazado na mais ampla tradição liberal dos juristas brasileiros" (BONAVIDES e PAES DE ANDRADE, 2006, p. 418). A questão é buscar compreender como a Justiça do Trabalho se insere nesse contexto.

A incorporação da Justiça do Trabalho no Poder Judiciário constitui fato relevante para a história do direito e do direito do trabalho no país. A história do direito, como afirma Andrei Koerner (2012, p. 633), "pode enfocar os institutos e doutrinas jurídicas de uma determinada época, pesquisando seu enraizamento político e social, a fim de realizar a crítica historicamente fundada das suas características e especificidades". Além disso, "o conhecimento das características de nossas instituições judiciais, a sua história, a formação da tradição, é passo essencial para a análise política de sua atuação na atualidade" (KOERNER, 2012, p. 637).5

A história do direito inclui a pesquisa sobre a história das instituições jurídicas. O presente artigo buscar analisar, nessa perspectiva, a Justiça do Trabalho e o percurso de sua consolidação, concentrando-se especificamente na mudança realizada pela Constituição de 1946. Assim sendo, cuida-se também de uma investigação no campo da história constitucional, em que a Constituição é apreendida como um produto histórico (SARASOLA, 2009, p.9).

A hipótese que orienta o texto é a de que a análise da incorporação da Justiça do Trabalho no Poder Judiciário, com a Constituição de 1946, representa um instrumental útil para se compreender as concepções então recorrentes sobre o direito do trabalho e a Justiça do Trabalho. De maneira específica, no debate sobre a integração ou não da Justiça do Trabalho ao Poder Judiciário, é possível observar uma relevante discussão a respeito da função (esperada ou desejada) dessa Justiça Especializada e do próprio direito do trabalho no país.

\footnotetext{
${ }^{4}$ Para a doutrina jurídico-trabalhista, é comum, na apresentação do desenvolvimento do direito do trabalho no Brasil, não haver referência ou, quando muito, uma simples menção à incorporação da Justiça do Trabalho no Poder Judiciário. Cf., a propósito, as obras, amplamente utilizadas nos cursos de direito, de Maurício Godinho Delgado (2014) e Mauro Schiavi (2016).
} 
Para empreender a análise proposta, o presente artigo se volta para as discussões na Assembleia Constituinte de 1946. A pesquisa se concentra nos diários da Constituinte, publicados no Diário do Poder Legislativo. Busca-se traçar o caminho dos principais debates sobre o tema - a Justiça do Trabalho e sua inclusão no Poder Judiciário -, até a aprovação final do texto.

O artigo se propõe a efetuar uma análise dos discursos proferidos pelos constituintes. Um problema a ser enfrentado, nessa tarefa, é o de como ler esses discursos. Tratando-se de textos (os diários da Constituinte), é necessário indagar seu sentido, tendo em vista os desafios inerentes a uma atividade interpretativa. Deve-se evitar a tentação de projetar o presente no passado (HESPANHA, 2005, p. 30), ou seja, é preciso enfrentar esse último como uma realidade distante. Um meio para tanto é buscar colocar o texto em seu devido contexto histórico. Como propõe Pietro Costa (2008, p. 25), "o historiador acumula os testemunhos para colocar o texto no tecido histórico-cultural do qual provém". Por conseguinte, prossegue o autor (2008, p. 25), "a lógica do historiador é uma dia-lógica: seu objetivo não é reduzir o outro a si mesmo, o passado ao presente, mas é instaurar um diálogo, usar todos os instrumentos disponíveis para entrar em relação com um mundo diverso do seu".

No campo da história do constitucionalismo, incumbe ao pesquisador "interligar as normas, as instituições e as doutrinas constitucionais com a sociedade na qual se inserem. Essa é uma conexão que lhe obriga a conhecer, ainda que apenas de forma instrumental, a realidade histórica de seu conjunto, sobretudo a política e a intelectual" (SUANZES-CARPEGNA, 2008, p. 14).

No caso do tema ora proposto, uma perspectiva produtiva para se ler os discursos dos constituintes de 1946 é fornecida por uma outra discussão historicamente relevante.

No processo de formação e implementação da Justiça do Trabalho, um debate, entre outros, se destaca: o que teve lugar entre Oliveira Viana, então Consultor Jurídico do Ministério do Trabalho de Getúlio Vargas, e Waldemar Ferreira, deputado federal e Professor da Faculdade de Direito da Universidade de São Paulo. O primeiro defendia a Justiça Trabalhista, impregnada de uma conotação social do direito e da vida pública; o segundo a criticava, em especial em razão de sua competência para alterar relações individuais, atuando como se legislativa fosse, em detrimento do princípio da separação de poderes.

A discussão entre Oliveira Viana e Waldemar Ferreira e as oposições nela presentes permitem identificar importantes perspectivas à época recorrentes sobre o Estado, o direito e a própria Justiça do Trabalho. Por isso, o debate entre ambos representa um relevante pano de fundo ideológico para apreender os discursos na Constituinte de 1946 e o confronto entre uma Justiça do Trabalho de caráter corporativo e um novo modelo de

\footnotetext{
${ }^{5}$ Tem-se em mente, por exemplo, as discussões que sobrevieram à aprovação da Lei no 13.467, de 13.7.2017, também denominada de "reforma trabalhista", acompanhadas de manifestações públicas propondo a extinção da Justiça do Trabalho. Essas questões são abordadas, entre outros, nos artigos de Valdete Souto Severo (2017) e Lênio Luiz Streck (2017).
} 
Estado, de tipo liberal democrático.

O artigo está estruturado em três partes. Na primeira, analisa-se a instituição da Justiça do Trabalho no Brasil, a partir de sua previsão na Constituição de 1934 até sua efetiva implementação em 1941, identificando-se a oposição de ideias que marcou a sua formação. O exame dessa oposição é aprofundado na segunda parte do texto, em que se apresenta o debate entre Oliveira Viana e Waldemar Ferreira. A terceira parte se destina a investigar os discursos na Assembleia Constituinte de 1946, quanto à Justiça do Trabalho e à sua incorporação no Poder Judiciário. Ao final, são apontadas algumas conclusões.

\section{A CONSOLIDAÇÃO DA JUSTIÇA DO TRABALHO NO BRASIL: DA PREVISÃO NA CONSTITUIÇÃO DE 1934 A SUA INCORPORAÇÃO NO PODER JUDICIÁRIO EM 1946}

Na história constitucional brasileira, a Constituição de 1934, em seu art. 122, foi a primeira a prever a instituição da Justiça do Trabalho, para "dirimir questões entre empregados e empregadores, regidas pela legislação social" (BRASIL, 1934). A composição dos Tribunais e das Comissões de Conciliação trabalhistas deveria observar o "princípio da eleição de membros, metade pelas associações representativas dos empregados, e metade pelas dos empregadores, sendo o presidente de livre nomeação do Governo (...)”. A Constituição de 1937, no art. 139, manteve a Justiça do Trabalho, prevendo sua regulação por lei e afastando as regras constitucionais sobre competência, recrutamento de magistrados e prerrogativas da Justiça Comum (BRASIL, 1937). Mas essa continuidade da Justiça especial nos dois textos constitucionais não ocorreu sem resistências.

Cumpre lembrar que, em 1932, já haviam sido instituídas as Juntas de Conciliação e Julgamento, para a solução de ações individuais, e as Comissões Mistas de Conciliação, para a de conflitos coletivos. Eram órgãos administrativos vinculados ao Poder Executivo, funcionando no âmbito do Departamento Nacional do Trabalho, que fora criado em 1931.

Uma das premissas da constituição das Juntas de Conciliação e Julgamento era a de que os conflitos entre empregados e empregadores não haviam tido, até então, um tratamento satisfatório, seja no Poder Judiciário Federal, seja no Poder Judiciário dos Estados. Daí a necessidade de uma Justiça do Trabalho, com um procedimento judicial adequado àqueles conflitos, o que incluía, em contraposição à Justiça Comum, um processo rápido, econômico, e uma organização paritária (isto é, com a participação de representantes de empregados e empregadores em seus órgãos). ${ }^{6}$

\footnotetext{
${ }^{6}$ Essas ideias são apresentadas na Exposição de Motivos do Decreto nº 22.132/1932, assinada pelo Ministro do Trabalho, Joaquim Pedro Salgado Filho (BRASIL, 1932).
} 
Angela de Castro Gomes (2006, p. 61) indica que a Justiça do Trabalho encontrava oposições decorrentes de compreensões liberais clássicas e individualistas, sendo defendida pelos apoiadores do autoritarismo estatal, apoio esse que, ao final, levou à sua preservação no Estado Novo e na Constituição de 1937, integrando-a em um projeto maior de uma estrutura corporativa. ${ }^{7}$

Uma primeira proposta de regulamentação da Justiça do Trabalho foi apresentada pelo governo em 1936. Essa proposta desencadeou uma importante discussão, reveladora dos interesses em disputa na instituição da Justiça Especial (MOREL e PESSANHA, 2007, p. 89). Os principais debatedores, como já apontado, foram o Consultor Jurídico do Ministério do Trabalho, Oliveira Viana, e o Presidente da Comissão de Constituição e Justiça da Câmara dos Deputados, Waldemar Ferreira. Entre os pontos mais sensíveis da contenda, estava o chamado poder normativo da Justiça do Trabalho, pelo qual as decisões proferidas, na solução de conflitos coletivos, produziriam normas jurídicas entre as partes litigantes. ${ }^{8}$

Morel e Pessanha (2007, p. 89/90) assim apresentam as correntes em disputa:

(...) de um lado, é possível caracterizar o modelo varguista de relações de trabalho, considerando que ele não só respondia a demandas sociais já existentes, mas também estava referido ao que pode ser entendido como um "consenso antiliberal", apoiado numa verdadeira concordância entre as correntes: socialistas, católicos e corporativistas, todos comprometidos, embora com objetivos e estratégias diferenciados, com a correção das desigualdades sociais da ordem capitalista por meio da ação do Estado.

De outro lado, tem-se a forte reação liberal à proposta apresentada, de que é exemplar a atuação, como relator, do renomado advogado civilista paulista Waldemar Ferreira na Comissão de Constituição e Justiça do Congresso Nacional. Os liberais não queriam uma justiça federal - tão distante e acima dos interesses locais bem sedimentados. Não queriam também que os sindicatos funcionassem como pessoas jurídicas públicas, alegando que a vontade individual dos trabalhadores deveria prevalecer. Não aceitavam, na verdade, a existência de sujeitos e direitos coletivos, e não queriam uma Justiça do Trabalho com o que consideravam o poder de legislar: eram frontalmente contra o poder normativo.

Com o Estado Novo e a Constituição de 1937, o confronto foi conduzido no sentido da manutenção da

Justiça do Trabalho e de seu poder normativo - acompanhados do endurecimento da estrutura sindical brasileira. Mas apenas em $1^{\circ}$ de maio de 1941, a Justiça Especializada foi efetivamente implantada (MOREL e PESSANHA, 2007, p. 90).

A Justiça do Trabalho entrou em funcionamento no âmbito do Ministério do Trabalho, organizada em três níveis. O primeiro era o das Juntas de Conciliação e Julgamento, presididas por um juiz de direito ou bacharel

\footnotetext{
${ }^{7}$ A vinculação da Justiça do Trabalho a esse projeto estatal corporativo é evidenciada, sobretudo, pela composição de seus órgãos, contando com os denominados juízes classistas ou vogais, representantes de empregados e empregadores (GOMES, 2006, p. 62). ${ }^{8}$ É o que previa o projeto de Lei Orgânica da Justiça do Trabalho, encaminhado em 1936 à Câmara dos Deputados, em seus artigos 20, "a”, e 6 (VIANA, 1983a, p. 147-148). Institucionalmente mantido mesmo pela Constituição de 1988, o poder normativo corresponde à competência reconhecida aos Tribunais Trabalhistas de definir normas que tratam de condições laborais nos processos denominados dissídios coletivos; em última análise, o exercício dessa competência se assemelha a uma atividade legiferante, pois o Tribunal estabelece às partes em conflito normas gerais e abstratas que vão disciplinar suas relações de trabalho. Para uma perspectiva crítica sobre o poder normativo, vale conferir a obra de Sayonara Grillo Coutinho Leonardo de Silva (2008).
} 
nomeado pelo Presidente da República. Eram compostas, ainda, pelos juízes classistas ou vogais, indicados pelas entidades sindicais de empregados e empregadores, com mandatos de dois anos. No segundo nível estavam os Conselhos Regionais do Trabalho, para julgamento dos recursos interpostos das decisões proferidas pelas Juntas de Conciliação e Julgamento. No cume estava o Conselho Nacional do Trabalho, em que, assim como nos Conselhos Regionais, também havia a representação de empregados e empregadores.

Passados pouco mais de quatro anos, em 29 de outubro de 1945, Getúlio Vargas foi deposto. Após a realização de eleições presidenciais e legislativas, Eurico Gaspar Dutra assumiu a Presidência da República, em janeiro de 1946. Algum tempo depois, o Congresso Nacional se reuniu em Assembleia Constituinte para discutir e aprovar uma nova Constituição. A Justiça do Trabalho foi objeto de importante debate na Constituinte de 1946. O resultado foi não apenas a sua preservação, mas também a sua desvinculação do Poder Executivo e do Ministério do Trabalho e a sua integração ao Poder Judiciário (com a manutenção de sua estrutura e competência, ou seja, a representação de empregados e empregadores em seus órgãos e o poder normativo).

Como observam, mais uma vez, Morel e Pessanha (2007, p. 91), "inserida no âmbito da Justiça Federal e, portanto, menos atrelada a interesses locais, a Justiça do Trabalho surge marcada pela natureza intervencionista e protecionista do Estado e, para isso, pretendia tutelar o trabalhador, definido como 'economicamente mais fraco'"

A Justiça do Trabalho havia sido implantada como uma forma de intervenção estatal na sociedade, em especial nos conflitos trabalhistas. Sendo acompanhada de uma estrutura sindical fortemente atrelada ao Estado, a Justiça Especial se inseria, assim, na organização corporativa instituída por Getúlio Vargas. ${ }^{9}$

$\mathrm{Na}$ Constituinte de 1946, as correntes liberais, que haviam feito oposição à Justiça do Trabalho, tinham oportunidade, nesse aspecto, de buscar romper com certos traços e características do Estado erigido por Getúlio Vargas. Wanderley Guilherme dos Santos (1978, p. 98) afirma que:

(...) depois da queda de Vargas, em 1945, todos os políticos que se consideravam liberais reuniram-se sob a bandeira da UDN - União Democrática Nacional -, cujo programa prático implicava que qualquer governo liberal, tanto no sentido econômico quanto político, deveria apagar todos os traços das políticas iniciadas por Vargas. As políticas trabalhista e econômica deveriam ser completamente revistas e modificadas. ${ }^{10}$

Entretanto, os elementos do Estado social foram preservados pelo novo texto constitucional. Gilberto Bercovici (2012, p. 393) observa que "a continuidade do 'constitucionalismo social' é garantida pela Constituição de 1946, embora com recuos (...)”.

A menção ao "constitucionalismo social" torna inevitável perquirir sobre a relação entre os textos de 1934 e de 1946. Aliomar Baleeiro (2001, p. 14) aponta a tendência, nesse último, de restauração "das linhas de

\footnotetext{
${ }^{9}$ Armando Boito Jr. $(1991,2002)$ associa a Justiça do Trabalho, sobretudo no que diz respeito à sua atuação perante sindicatos e negociações coletivas, à própria estrutura sindical.
} 
1891 com as inovações aproveitáveis de 1934". Para Barbosa Lima Sobrinho (2001, p. 33), por sua vez, não houve, entre os constituintes de 1946, o propósito de uma imitação do texto de 1934, tendo ocorrido, em verdade, uma semelhança de "fatores políticos", orientando a elaboração da Constituição, em 1934 e 1946, "pelo pensamento de uma reação contra os exageros do presidencialismo da República, ou contra as tendências ditatoriais, que modelaram a Carta de 1937".

Duas manifestações importantes na Constituinte de 1946 confirmam essa perspectiva. Ao tomar posse como Presidente da Assembleia Constituinte, Fernando de Melo Viana (PSD/MG) discursou, invocando as tradições políticas e religiosas do país, referindo-se a "vibrações de patriotismo" presentes naquele "ambiente de esperanças". Havia, em suas palavras, um tom de restauração do regime anterior a 1937 (BRASIL, 1946a, p. 1819). Já Hermes Lima (ED/DF), na primeira sessão da Comissão da Constituição, afirmou que a Constituinte não seria revolucionária e deveria manter os fundamentos econômico-jurídicos que até então tinham vigorado no país. Sua referência era também o regime existente antes de 1937 (BRASIL, 1946b, p. 447).

Nessa tensão entre continuidade e ruptura, matizada por uma restauração da Constituição de 1934, temse a desvinculação da Justiça do Trabalho do Poder Executivo e sua incorporação no Poder Judiciário, com a manutenção de sua estrutura e competência, inclusive a normativa. Tal mudança se relaciona de forma direta com o papel a ser desempenhado pela Justiça do Trabalho e pelo direito do trabalho.

Segundo Luiz Werneck Vianna (1989, p. 270):

apesar da continuidade com a ordem anterior, o pós-46 operava uma importante diferenciação nas relações entre o Estado, o capital e o trabalho. No Estado Novo, era o Ministério do Trabalho acoplado aos sindicatos a peça que ordenava e amparava todo o sistema da CLT. Agora, esse papel se transferia para a Justiça do Trabalho, cuja competência normativa se constituía no eixo da política para as classes subalternas.

Para se abordar a modificação realizada em 1946 e os discursos havidos em torno dela, é importante retomar as ideias em disputa sobre a própria implementação da Justiça do Trabalho. Isso será realizado, no item a seguir, a partir do debate entre Oliveira Viana e Waldemar Ferreira.

\section{O DEBATE ENTRE OLIVEIRA VIANA E WALDEMAR FERREIRA: A JUSTIÇA DO TRABALHO ENTRE DIFERENTES CONCEPÇÕES DE DIREITO E ESTADO.}

Um dos principais autores da legislação social do governo de Getúlio Vargas foi Oliveira Viana. Influenciado por Sílvio Romero e Alberto Torres, ele estudou com profundidade a formação política e social do Brasil. Suas opiniões sobre temas como sindicatos e trabalhadores, aprofundadas em face da sua ocupação com o

\footnotetext{
${ }^{10}$ Como será visto mais à frente, porém, mesmo constituintes da UDN defenderam a manutenção da Justiça do Trabalho e sua incorporação no Poder Judiciário.
} 
direito do trabalho, a partir de 1930, inserem-se de forma coerente no conjunto de seu pensamento sobre a sociedade brasileira e o papel do Estado. Tendo atuado como Consultor Jurídico no Ministério do Trabalho de 1932 a 1940, sua importância no governo Vargas é destacada por inúmeros autores (FAUSTO, 2001 e WEFFORT, 2006), e seu pensamento influenciou de maneira decisiva a formação e a consolidação do direito do trabalho e da Justiça do Trabalho no país. ${ }^{11}$

No final de 1936, quando Oliveira Viana ainda integrava o Ministério do Trabalho, o Presidente da República, Getúlio Vargas, encaminhou ao Poder Legislativo o projeto de Lei Orgânica da Justiça do Trabalho. Na Comissão de Constituição e Justiça, o projeto foi distribuído a Waldemar Ferreira, conhecido civilista e Professor de Direito da Universidade de São Paulo - USP. ${ }^{12}$ Waldemar Ferreira (1938) elaborou um parecer, analisando e criticando diversos aspectos do projeto. Em resposta, Oliveira Viana (1983b) publicou uma série de artigos, rebatendo as críticas daquele. A discussão entre os dois é reveladora do que estava por trás da implementação e da função da Justiça do Trabalho.

Waldemar Ferreira (1938, p. 220), tomando por base a Constituição de 1934, apresentava sérias ressalvas à competência normativa da Justiça do Trabalho, entendendo que havia violação ao princípio da separação dos poderes. Para o civilista, era inconstitucional o preceito do anteprojeto que tratava do poder normativo, na medida em que o Poder Legislativo não poderia delegar à Justiça Especializada sua competência privativa de legislar. Seu parecer acentuava que, no Brasil, a Justiça do Trabalho teria feição "nitidamente jurisdicional", de maneira que não poderia alterar contratos de trabalho, individuais ou coletivos. Ao mesmo tempo, porém, Waldemar Ferreira (1938, p. 195-196) criticava o dispositivo do anteprojeto que permitia aos Tribunais do Trabalho dissolver, com base na legislação social, associações profissionais, uma vez que, pela Constituição, apenas o Poder Judiciário poderia decidir sobre isso. ${ }^{13}$

O professor da USP (1938, p. 125) reconhecia a natureza especial da Justiça do Trabalho, cujas características, de acordo com o texto constitucional de 1934, seriam: "a especial constituição dos órgãos judiciários", "a especialidade da matéria", "a qualidade profissional das pessoas: empregados e empregadores" e "a especialidade do processo, com adoção do procedimento oral". Em sua opinião, "não existe, nem pode existir, em tais condições, justiça mais especial que a Justiça do Trabalho". No entanto, o civilista (1938, p. 231) externava a

\footnotetext{
${ }^{11}$ Em entrevista concedida a Magda Barros Biavaschi (2005, p. 132), Arnaldo Süssekind, um dos integrantes da comissão que elaborou a Consolidação das Leis do Trabalho - CLT, de 1943, aponta, como uma das fontes materiais dessa Consolidação, os pareceres de Oliveira Viana proferidos nas “avocatórias", no bojo de reclamações apresentadas perante o Ministério do Trabalho. ${ }^{12}$ Waldemar Ferreira era deputado federal pelo Partido Constitucionalista de São Paulo. Posteriormente, foi um dos fundadores da União Democrática Nacional - UDN. Sua biografia pode ser consultada no Portal do Centro de Pesquisa e Documentação de História Contemporânea do Brasil da Fundação Getúlio Vargas (s/d - disponível em http://www.fgv.br/cpdoc/acervo/dicionarios/verbete-biografico/valdemar-martins-ferreira - acesso em 20.1.2018).

${ }^{13}$ Tratava-se das disposições relativas às penalidades, previstas no Título VII do anteprojeto (VIANA, 1983a, p. 165-169).
} 
opinião de que a jurisdição trabalhista deveria ser atribuída a juízes comuns: "nada impede que na mesma pessoa natural se concentrem as duas investiduras, subordinadas, embora, a princípios diferentes".

Waldemar Ferreira, embora reconhecesse as peculiaridades da Justiça do Trabalho e dos princípios que orientavam a aplicação da legislação social, e mesmo afirmando sua feição jurisdicional, não a apreendia como se devesse integrar o Poder Judiciário. Apontava, por um lado, a inconstitucionalidade do poder normativo e, por outro, defendia a atribuição da jurisdição trabalhista a magistrados da Justiça Comum.

Para Oliveira Viana (1983b, p. 21-22), por sua vez, as assertivas de Waldemar Ferreira revelavam um conflito entre duas concepções do direito: a concepção individualista, de um lado, e a nova concepção, resultante da então crescente socialização da vida jurídica, de outro. O direito saído da Revolução de 1930 não seria compatível com as regras, os princípios e o sistema do direito privado. Segundo Oliveira Viana (1983b, p. 38), os críticos haviam feito uma interpretação do art. 122 da Constituição de 1934 sem considerar os aspectos sociais e políticos da Justiça do Trabalho: "ora, nem o conteúdo político do texto, nem a novidade das instituições criadas e admitidas pela primeira vez, nada disto foi considerado".

Utilizando exemplos estrangeiros - em especial dos Estados Unidos da América $-{ }^{14}$, o Consultor Jurídico do Ministério do Trabalho (1983b, p. 55) criticava de forma veemente "a velha dogmática do Estado Liberal" (de que teria feito uso Waldemar Ferreira), como incapaz de apreender o sentido de novidade da instituição da Justiça do Trabalho.

Oliveira Viana (1983b, p. 56) buscava demonstrar sua tese sobre as atribuições da Justiça do Trabalho adotando como parâmetro as corporações administrativas norte-americanas, que teriam passado a regular importantes aspectos da vida social e econômica dos Estados Unidos, inclusive os conflitos de trabalho, individuais e coletivos. O fundamento dessas instituições seria a eficiência do serviço público. Na observação de Oliveira Viana (1983b, p. 56), "daí este movimento, que vemos se processar na vida das administrações americanas, federais e estaduais, no sentido de libertar a solução destas questões das complicadas e morosas formalidades processualísticas dos tribunais propriamente judiciários". A argumentação evidenciava a inspiração administrativa para a Justiça do Trabalho. Não obstante, Oliveira Viana (1983c, p. 176) considerava um equívoco a opção do constituinte de 1934 por excluir a Justiça do Trabalho do Poder Judiciário.

A função normativa dos Tribunais Trabalhistas seria, de toda forma, compatível com a judiciária. Para Viana (1983b, p. 72), a alegação contrária - presente no parecer de Waldemar Ferreira - decorreria da utilização, para os órgãos da Justiça do Trabalho, de regras e princípios do direito judiciário e processual típicos dos tribunais de direito comum. Entretanto, "enquadrar a Justiça do Trabalho na metodologia processual dos tribunais de

\footnotetext{
${ }^{14}$ Sobre o papel muitas vezes instrumental das referências a autores estrangeiros nos estudos de Oliveira Viana, conferir o artigo de José Murilo de Carvalho (1991, p. 85).
} 
direito comum é, pois, uma contradição substancial, que importaria em anular a própria razão de ser da sua instituição". O direito do trabalho, segundo Oliveira Viana (1983b, p. 37), não deveria ser interpretado a partir de critérios, regras ou princípios civilistas ou próprios dos tribunais de direito comum.

A crítica de Oliveira Viana se voltava, em especial, à interpretação dos artigos 121 e 122 da Constituição de 1934, feita por Waldemar Ferreira e outros parlamentares. Na sua opinião (1983b, p. 37):

é o pleno regime do civilismo, do comercialismo, do processualismo, do praxismo, do formalismo jurídico - da 'Pandectologia mumificada', de ironia de Wilhem Sauer. É o império soberano da Praxe Forense, de Ramalho, e da Hermenêutica, de Paula Baptista. Puro jogo de silogismos abstratos. Um texto constitucional - túmido, até quase a rebentar, de significado político e social - reduzido aos termos de uma pura equação algébrica (...) (grifos no original)

Para Oliveira Viana, a competência normativa se relacionava com o caráter corporativo da Justiça Trabalhista. Em sua constatação (1983c, p. 179), "os órgãos corporativos criados para regular e disciplinar os conflitos econômicos e sociais estão cada vez mais investidos de funções normativas". Nesse sentido, ainda em suas palavras (1983c, p. 190), "em direito corporativo [...], é princípio dominante que as organizações corporativas, quando porventura instituídas, ficam investidas de um poder 'autônomo' para editar normas reguladoras das relações da categoria, a que pertencem".

No caso da Justiça do Trabalho, esse poder decorreria da própria Constituição de 1934, na medida em que, "estabelecendo o regime corporativo para organizações judicantes dos dissídios do trabalho, está claro que a Constituição concedeu, implicitamente, poderes a estas corporações para regular, de maneira geral, quando assim julgarem conveniente, a matéria da sua competência” (VIANA, 1983c, p. 190).

Para Viana, era necessário, na leitura da Constituição de 1934, utilizar outros parâmetros interpretativos. Em uma passagem expressiva, o autor (1983b, p. 34) revela o apelo a um direito não-formal, afirmando que:

ora, nas doutrinas alemãs mais recentes do Direito Público, ao contrário da concepção de [Hans] Kelsen, domina (...) o pensamento quase unânime de que a construção lógicoformal dos conceitos jurídicos não é possível por meio do emprego exclusivo de proposições lógicas; mas, que se faz preciso apelar para os dados de natureza política, principalmente quando se trata de conceitos ou preceitos de Direito Constitucional e Administrativo.

As oposições e os antagonismos entre Oliveira Viana e Waldemar Ferreira refletem diferentes concepções sobre o direito, o Estado e, conectada a isso, a função da Justiça do Trabalho.

Percebe-se no texto de Waldemar Ferreira uma preocupação com a ação do Estado em determinados aspectos da vida social. Ele apreende com ressalva, por exemplo, a possibilidade de alteração de contratos individuais ou coletivos por meio de decisão do Poder Público, como seria a consequência do exercício da competência normativa da Justiça do Trabalho. Tem-se a denúncia da violação ao princípio da separação dos poderes, diante da delegação da função legislativa. Waldemar Ferreira considerava problemática a possibilidade de um órgão administrativo, como era então a Justiça do Trabalho, dissolver associações profissionais - o que deixa 
transparecer sua preocupação, em última análise, com a garantia do direito à livre associação (direito esse oponível, antes de tudo, ao Estado).

Já para Oliveira Viana, seria necessário considerar, na interpretação da Constituição de 1934, a novidade da socialização da vida jurídica e, por consequência, da própria implementação da Justiça do Trabalho. Por meio de instituições corporativas como essa última, ter-se-ia a regulação estatal de aspectos relevantes da vida econômica e social. Parte-se aqui da concepção de um Estado que intervém na sociedade, inclusive na relação entre capital e trabalho, para solucionar e disciplinar os conflitos aí existentes.

$\mathrm{Na}$ base do pensamento de Oliveira Viana estava a premissa de que incumbia ao Estado o papel de organizador da sociedade brasileira (BRASIL JR, 2010, p. 303 e SANTOS, R., 2010, p. 297). Essa condução estatal, com a centralização do poder político, a evidenciar a opção por uma forma de autoritarismo, seria o instrumento necessário para que fosse viabilizado o liberalismo político (SANTOS, W., 1978, p. 106). ${ }^{15}$

No debate entre Oliveira Viana e Waldemar Ferreira, é possível observar uma importante oposição de ideias: por parte do primeiro, a valorização de um direito público e social, não obstante encerrado no Estado, e que atribui a esse a função de conduzir a vida em sociedade, organizando-a em suas formas de representação e nos meios de apresentação de interesses; e, por parte do segundo, uma ênfase no direito privado e na atuação individual dos cidadãos, a rejeitar uma intervenção mais significativa do Estado na sociedade. Essa oposição de ideias entre Oliveira Viana e Waldemar Ferreira matiza, respectivamente, a defesa e a crítica da Justiça do Trabalho e de sua atuação, sobretudo no que diz respeito à sua função normativa (que, como indicava Oliveira Viana, seria uma função própria de um órgão de natureza corporativa).

Os parâmetros do diálogo e das dicotomias entre os dois pensadores vão se projetar mais à frente, na Assembleia Constituinte de 1946 e nas discussões sobre a Justiça do Trabalho. É o que será analisado no próximo tópico.

\section{AS DISCUSSÕES NA ASSEMBLEIA CONSTITUINTE DE 1946: A MANUTENÇÃO DA JUSTIÇA DO TRABALHO SOB A IDEIA DE UM CONSTITUCIONALISMO SOCIAL}

Os debates ocorridos na Assembleia Constituinte de 1946 sobre a Justiça do Trabalho revelam oposições - como público e privado, individual e coletivo (ou social), Justiça Comum e Justiça Especial - que indicam uma relação complexa dos constituintes com o regime anterior. Isso ocorria talvez porque diversos deles

\footnotetext{
${ }^{15}$ A opção de Viana pelo autoritarismo estava relacionada à característica do "insolidarismo" que ele atribuía à sociedade brasileira. Essa noção é bem desenvolvida em sua obra Populações Meridionais do Brasil(2005).
} 
tivessem participado, em algum momento, inclusive durante o Estado Novo, do governo de Getúlio Vargas.

Muitos constituintes - inclusive o próprio Getúlio Vargas - pertenciam ao partido de sustentação do governo, o Partido Social Democrático - PSD, que vencera as eleições para a Presidência da República com Eurico Gaspar Dutra. E tanto no partido governista, como no Partido Trabalhista Brasileiro - PTB e também no âmbito de partidos de oposição, como a União Democrática Nacional - UDN e o Partido Comunista do Brasil PCB,${ }^{16}$ é possível perceber uma significativa adesão aos ideais que motivaram a instituição da Justiça do Trabalho e, na Constituinte, ensejaram sua incorporação no Poder Judiciário.

É chegado o momento de traçar o caminho dos debates sobre a Justiça do Trabalho, seguindo o andamento das atividades da Assembleia de 1946.

$\mathrm{Na}$ Constituinte, a Comissão incumbida de redigir o projeto de Constituição, para submissão ao Plenário, debateu a integração da Justiça do Trabalho no Poder Judiciário na reunião de 26 de abril de $1946 .{ }^{17}$

A Subcomissão V, encarregada do capítulo sobre o Poder Judiciário, ${ }^{18}$ havia apresentado à Comissão anteprojeto incluindo a Justiça do Trabalho no âmbito do Poder Judiciário. ${ }^{19}$ Já na Comissão, Ferreira de Sousa (UDN/RN) apresentou emenda supressiva, excluindo aquela previsão do texto. Para o constituinte, "se [as relações de trabalho] são relações comuns não vejo porque, constitucionalmente, se crie Justiça especial e não se atribuam os dissídios consequentes ao julgamento da Justiça comum" (BRASIL, 1946e, p. 1.286). ${ }^{20}$ Ferreira de Sousa questionava o que haveria de inovador no campo do direito do trabalho, e expressava sua preferência pela opção feita nas Constituições de 1934 e 1937, não incluindo a Justiça do Trabalho no Poder Judiciário (BRASIL, 1946e, p. 1286-1287).

Fez uso da palavra, na sequência, Agamenon Magalhães (PSD/PE), que, depois de referir à "verdadeira revolução nos conceitos do direito privado", ressaltou a especificidade da Justiça Trabalhista, destacando a competência normativa e a conciliação, como peculiaridades para não integrá-la à Justiça Comum. Em sua visão, "a Justiça do Trabalho é normativa e suas decisões, nos conflitos coletivos, obrigam a todos os ramos de determinada indústria a tôda uma classe, enquanto a Justiça togada só julga em espécie, só decide entre partes". Daí a consequência: "se procurarmos integrar a Justiça do Trabalho, cuja jurisdição é específica, no campo da

\footnotetext{
${ }^{16}$ Sobre a situação e os dilemas desses dois partidos de oposição no período que antecedeu a Constituinte de 1946, ver a descrição de Thomas Skidmore (2007, p. 83-89).

${ }^{17}$ A Comissão da Constituição era integrada por 37 constituintes (sendo 19 do PSD e 10 da UDN) e foi presidida por Nereu Ramos (PSD/SC), que, ao final dos trabalhos da Assembleia Constituinte, viria a ser eleito o Vice-Presidente da República de Eurico Gaspar Dutra.

${ }^{18}$ A Subcomissão V era composta pelos constituintes Valdemar Pedrosa (PSD/AM), presidente, Milton Campos (UDN/MG), relator, e Atílio Vivácqua (PSD/ES).

${ }^{19}$ Ainda na fase das reuniões da Subcomissão V, a ata da reunião do dia 21.3.1946 faz menção a algumas sugestões recebidas, entre elas a do constituinte Plínio Barreto (UDN/SP) para a inclusão da Justiça do Trabalho entre os órgãos do Poder Judiciário (BRASIL, 1946c, p. 537).
} 
Justiça comum, terá ela fugido completamente aos seus princípios". O constituinte enfatizou, ainda, a "organização paritária dos Tribunais" trabalhistas, a permitir a representação de "todos os interesses" (BRASIL, 1946e, p. $1.287) \cdot{ }^{21}$

Em seguida, porém, vários constituintes fizeram uso da palavra para defender o caráter jurisdicional da Justiça do Trabalho. De acordo com Ataliba Nogueira (PSD/SP), por sua vez, a Justiça do Trabalho seria "órgão do Poder Judiciário", e deveria ser evitado o erro de conferir questões de julgamento a juízes e tribunais fora do Poder Judiciário. Para o constituinte, a especialização da Justiça do Trabalho estaria justificada na "celeridade no andamento dos feitos" e, por conseguinte, tratando-se de uma Justiça "especial" poderia receber "uma organização tôda especial". Ataliba Nogueira expressava a ideia de que "o momento histórico está a exigir a Justiça do Trabalho" e de que "é necessária a justiça do trabalho, paritária e portadora de outros benefícios [...]". Nela deveria ser assegurada, ainda, "a interferência de juízes togados para presidir os julgamentos" (BRASIL, 1946e, p. 1.287).

Baeta Neves (PTB/DF), na mesma linha, criticou a posição de Ferreira de Souza quanto à possibilidade de atribuição dos dissídios trabalhistas à Justiça Comum. Baeta Neves defendia a Justiça do Trabalho como importante instituição para o país, afirmando que seu funcionamento deveria ser regulado no capítulo da Constituição destinado à ordem econômica e social (BRASIL, 1946e: 1.287).22

Essa última opinião merece ser destacada. A questão da localização da disciplina da Justiça do Trabalho no texto constitucional também se fará presente na fala de outros parlamentares, como será visto adiante, o que denota sua importância nos debates. Ao mesmo tempo, vale notar que ela está relacionada à compreensão dos constituintes sobre o papel daquela Justiça, ou seja, um instrumento de atuação na ordem econômica e social.

Prosseguindo nas discussões, Ivo D’Aquino (PSD/SC) referiu à Justiça do Trabalho como "a maior conquista que o Brasil realizou nestes últimos anos". Para o constituinte, era necessário reconhecer que o "direito político", "por exigências de ordem social", estava "penetrando, inelutavelmente, no campo do direito privado". Ivo D’Aquino advertiu então: "peço a atenção desta Comissão, porque a nossa Constituição terá de ser orientada num pensamento social-democrático. Ou caminhamos para ela ou teremos de dar lugar a outro regime que promete solução social, que estamos negando neste momento" (BRASIL, 1946e, p. 1.287-1.288). ${ }^{23}$

Costa Neto (PSD/SP) criticou as bases do discurso de Agamenon Magalhães, mas concordou com suas conclusões. Segundo ele, o direito teria certos pressupostos: o direito público pressuporia o Estado; o direito

\footnotetext{
${ }^{20}$ Todas as transcrições foram realizadas tal como constam dos diários da Assembleia Constituinte.

${ }^{21}$ O constituinte fora Ministro do Trabalho, Indústria e Comércio (1934-1937) e da Justiça (março a outubro de 1945) de Getúlio Vargas (BRAGA, 1998, p. 486).

${ }^{22}$ Baeta Neves era advogado trabalhista e fora membro de entidades sindicais dos comerciários, tendo atuado também como primeiro suplente da Justiça do Trabalho na 1a Região (BRAGA, 1998, p. 261-262).

${ }^{23}$ Essa manifestação também corrobora o que foi indicado mais acima sobre a intenção de restauração do regime anterior ao Estado Novo.
} 
social, expressão preferível a direito do trabalho, pressuporia a sociedade; e o direito privado, o indivíduo. No caso da Justiça do Trabalho, sua existência estaria justificada na solução dos dissídios individuais e coletivos, para o que se mostraria mais adequada do que a Justiça Comum (BRASIL, 1946e, p. 1.288).

Silvestre Péricles (PSD/AL), como já havia feito em discussão anterior (BRASIL, 1946d, p. 1251), defendeu a manutenção do dispositivo do projeto, enfatizando o caráter coletivo e socialista da Justiça do Trabalho, opondo-se à Justiça Comum, de feição individualista. Em suas palavras, "a denominada justiça comum é a clássica justiça individualista, da época do direito romano. A justiça do trabalho está, ao contrário, em franco desenvolvimento, representando a justiça de conjunto, a justiça coletiva ou socialista”. Era, a Justiça do Trabalho, uma instituição que já havia tomado seu lugar na sociedade (BRASIL, 1946e, p. 1.288). ${ }^{24}$

Adroaldo Mesquita (PSD/RS), ao se manifestar de forma favorável à inclusão da Justiça do Trabalho no Poder Judiciário, defendeu - assim como já havia feito Baeta Neves - que sua regulamentação deveria se dar no capítulo atinente à ordem econômica e social. Além disso, em sua opinião, a representação de empregados e empregadores na Justiça do Trabalho teria uma função consultiva, fornecendo subsídios ao juiz (togado) para a decisão do caso. Mas a peculiaridade da Justiça Trabalhista viria de outro aspecto: "o que não posso é deixar de fazer da Justiça do Trabalho uma justiça autônoma, porque, para isso, tem ela a competência normativa, coisa que não é dada à justiça comum" (BRASIL, 1946e: 1.288).

É possível notar, nessas manifestações, a ênfase conferida à conotação social da Justiça do Trabalho e do direito do trabalho, conotação que seria específica, na visão de parte dos constituintes, do momento histórico vivido. As oposições, fazendo eco ao debate entre Oliveira Viana e Waldemar Ferreira, vão se explicitando nos discursos: direito público, coletivo e social, de um lado, associado à Justiça do Trabalho e ao direito do trabalho; direito privado, comum, individual, do outro lado, característico da Justiça Comum. E é nítido o pendor dos constituintes pelo primeiro dos polos em confronto.

Em meio a essas oposições, o poder normativo da Justiça do Trabalho, relevante, em especial, para o tratamento dos conflitos coletivos, era normalizado nos discursos dos constituintes. Não havia, ou não eram expressadas, oposições mais relevantes àquela competência normativa. Percebe-se, ainda, que não havia significativas intenções de alterar quer o funcionamento quer a estrutura da Justiça do Trabalho. Ao mesmo tempo, acentuava-se que a questão da Justiça do Trabalho dizia respeito ao campo econômico-social, como se infere das opiniões no sentido de que a regulamentação dessa Justiça Especializada deveria se dar no capítulo do texto constitucional atinente à ordem econômica e social.

\footnotetext{
${ }^{24}$ Silvestre Péricles de Góis Monteiro era irmão do General Pedro Aurélio de Góis Monteiro e considerado, por Sérgio Braga (1998, p. 159-160), como "alter ego" desse último na Assembleia Constituinte. Foi, ainda, Presidente do Conselho Nacional do
} 
Esses aspectos vão permear, com maior ou menor intensidade, os discursos dos demais constituintes.

Na sequência dos debates, Prado Kelly (UDN/RJ) discordou da emenda oferecida por Ferreira de Sousa e afirmou, em nome do Partido, que considerava que o direito moderno seria cada vez mais "dominado pelas relações sociais". Lembrou que a previsão da Constituição de 1934 sobre a Justiça do Trabalho contara com sua participação, também como constituinte. Em sua visão, na redação do novo texto constitucional, não deveriam ser adotadas restrições à especialização da Justiça do Trabalho (BRASIL, 1946e, p. 1.288).

Hermes Lima, único representante, na Comissão, da Esquerda Democrática (ED/DF), ${ }^{25}$ ressaltou a importância da questão debatida, indicando que não poderia ser diferente: a Justiça do Trabalho era um órgão do Poder Judiciário na medida em que tem "o poder de executar suas próprias decisões". Além disso, seria específico das atribuições da Justiça do Trabalho seu "caráter normativo". Hermes Lima também destacou a relevância da Justiça Trabalhista como conquista do país e para a manutenção da paz social, porque relacionada à solução dos conflitos entre o capital e o trabalho. Para o constituinte, "exatamente porque é uma Justiça chamada a resolver questões sociais originárias de conflitos entre o capital e o trabalho, foi-lhe dada essa autonomia, essa normatividade, essa especialização, êsse caráter paritário" (BRASIL, 1946e, p. 1.288-1289).

Aliomar Baleeiro (UDN/BA) rebateu a assertiva de Agamenon Magalhães de que a especificidade da Justiça do Trabalho consistiria em seu caráter normativo. E conceituou a Justiça Trabalhista como "órgão administrativo com função jurisdicional, o que não seria privativo dela". Assim, "já que a Justiça do Trabalho é um órgão jurisdicional, que aplica o mesmo direito, seu lugar deve ser dentro do próprio Poder Judiciário, mesmo porque somos país infenso à justiça administrativa" (BRASIL, 1946e, p. 1.289).

Caires de Brito (PCB/SP) também se pronunciou favoravelmente à integração da Justiça do Trabalho ao Poder Judiciário. Para ele, haveria vantagens em se manter "a justiça especializada com sua autonomia, tirandoa, do contrôle absoluto do Ministério do Trabalho, e não a deixando simplesmente na justiça comum". O contexto brasileiro, de início de industrialização, justificaria uma Justiça do Trabalho com maiores prerrogativas e autonomia. De acordo com o constituinte, as relações de produção, no país, seriam diferentes das existentes "em países de fase industrial mais avançada"; e "os problemas são grandes e - não tenhamos dúvidas - só haverá vantagem em que permaneça a justiça do trabalho como está, - autônoma, em condições de poder mover número considerável de processos". Caires de Brito lembrou a importância de a Justiça do Trabalho atuar de maneira célere. Mas a questão dependeria também do governo, pois "a justiça do trabalho só será eficazmente melhorada faço justiça ao que já se tem conseguido - à proporção que o Govêrno possa e queira proteger realmente os

Trabalho de 1941 a 1943. Após a constituinte, elegeu-se governador de Alagoas, onde promoveu forte repressão ao movimento popular (BRAGA, 1998, p. 169-170). 
interessados e necessitados dela", bem como da garantia de direitos sindicais, na medida em que "a condição para a justa aplicação da justiça do trabalho está em se dar aos sindicatos liberdades e garantias, como órgãos de classe" (BRASIL, 1946e, p. 1.289).

Manifestou-se, em seguida, Atílio Vivácqua (PSD/ES), ressaltando a autonomia do direito do trabalho, do que decorria a própria magistratura trabalhista, como diversidade das técnicas e dos métodos de solução de conflitos. Justificou a necessidade de uma magistratura especial, com representação paritária de empregados e empregadores, diante das decisões a serem proferidas em conflitos coletivos, e destacou a "longa experiência" da Justiça do Trabalho no país, desde as Juntas de Conciliação formadas em 1932, observando que: "[...] neste momento, reconhecemos apenas experiência comprovada pelos mais benéficos resultados. Neste instante de conflitos sociais, foi providencial que o país, no após guerra, já se encontrasse dotado de órgãos capazes de servir de instrumento de pacificação coletiva”. Em sua visão, a Justiça do Trabalho cumpriria seu papel na conciliação entre empregados e empregadores, como "fator de equilíbrio social" (BRASIL, 1946e, p. 1.289-1.290). ${ }^{26}$

Como se constata nesses discursos, a competência normativa não se mostrou um óbice à manutenção da Justiça do Trabalho, apreendida, essa última, como um importante instrumento de justiça e democracia social, relacionada a um direito social, público, coletivo. Sua função estaria conectada à manutenção da paz na sociedade, em atenção ao conflito entre capital e trabalho. Talvez por isso, como um desdobramento natural, tinham-se as opiniões no sentido de que sua regulamentação deveria ser situada no capítulo da Constituição destinado à ordem econômico-social.

Procedida a votação na Comissão, a emenda de Ferreira de Sousa foi rejeitada. Mais à frente nas discussões, foi aprovada emenda de Adroaldo Mesquita (PSD/RS) que visava a garantir o reconhecimento da competência normativa da Justiça do Trabalho. Essa competência foi, então, apresentada como essencial para que a Justiça Trabalhista não ficasse inoperante e ineficiente (BRASIL, 1946f, p. 1387).

Na discussão em Plenário do projeto de Constituição, formulado pela Comissão, não houve debates significativos sobre a previsão da Justiça do Trabalho como órgão do Poder Judiciário. O momento decisivo havia sido na chamada "Grande Comissão". Ao final, houve a inserção da Justiça Trabalhista no âmbito do Poder Judiciário, como estipulado no art. 94 da Constituição (BRASIL, 1946), com sua consequente desvinculação do Poder Executivo.

Se, como indicam alguns intérpretes da Constituição de 1946, a Constituinte procurou decotar os excessos do Estado Novo e do Poder Executivo, a Justiça do Trabalho certamente não entrou nesse rol; quando

\footnotetext{
${ }^{25}$ Hermes Lima, advogado e professor universitário, fora perseguido político no Estado Novo. Com o fim desse, participou da fundação da UDN e foi um dos principais organizadores da ED (BRAGA, 1998, p. 281).
} 
muito, foi reconhecida a importância de sua desvinculação do Poder Executivo e do Ministério do Trabalho, de maneira a reforçar sua autonomia e sua independência.

A continuidade do constitucionalismo social, que remontava à Constituição de 1934, incluiu, portanto, a preservação da Justiça do Trabalho, com sua estrutura corporativa e sua competência normativa. Associado a essa Justiça, estava um ramo do direito, o direito do trabalho, sendo, ambos, apreendidos como impregnados de uma concepção de direito público, coletivo, social, em contraposição ao direito comum, individual, e à Justiça Comum.

\section{CONCLUSÕES}

A análise dos debates da Assembleia Constituinte de 1946 indica que a oposição liberal à implementação da Justiça do Trabalho cedeu lugar a uma preponderância de ideias que enfatizavam a necessidade e a importância da Justiça do Trabalho e do direito do trabalho, como expressões de um direito público, social, coletivo, relevantes para a solução dos conflitos entre empregados e empregadores.

A Justiça do Trabalho, incluindo sua composição corporativa (com a representação, em seus órgãos, de empregados e empregadores) e seu poder normativo, foi normalizada pela Constituição de 1946, que a integrou ao Poder Judiciário. Ainda que o texto constitucional revele traços liberais, como apontam alguns autores, a Justiça Trabalhista foi preservada, a par de suas características.

A função normativa da Justiça do Trabalho e sua estrutura corporativa não estavam no conjunto de excessos do regime varguista com o qual os constituintes de 1946 pretendiam romper. Na prática, a principal ruptura, nesse campo, se deu por meio da desvinculação da Justiça Trabalhista quanto ao Poder Executivo e ao Ministério do Trabalho. A continuidade (ou a restauração) do constitucionalismo social de 1934 envolvia a Justiça do Trabalho e o direito do trabalho.

A despeito da discussão sobre se a Constituição de 1946 é ou não preponderantemente liberal, o fato é que, como explicita a análise acima, remontando ao debate entre Oliveira Viana e Waldemar Ferreira, foi mantida a Justiça do Trabalho - embora agora integrada ao Poder Judiciário - como instrumento de atuação (estatal) na ordem econômico-social. Isso conduz a uma outra questão, também importante, que diz respeito à finalidade dessa atuação.

A utilização, pelos constituintes, de expressões como "paz social" e "justiça social", entre outras

\footnotetext{
${ }^{26}$ Atílio Vivácqua fora Procurador da Justiça do Trabalho e Consultor Jurídico do Ministério do Trabalho, Indústria e Comércio e da Companhia Siderúrgica Nacional (BRAGA, 1998, p. 303).
} 
equivalentes, a ênfase na conciliação e até mesmo a defesa da função normativa evidenciam uma preocupação acentuada com a solução dos conflitos entre empregados e empregadores. Na visão dos constituintes, seria necessária a constituição de órgãos estatais aptos para essas questões. E apenas uma justiça de viés social, coletiva, que aplicasse um ramo do direito também imbuído dessas características, seria adequada para resolver os conflitos sociais específicos das relações laborais. A Justiça do Trabalho e o direito do trabalho aparecem, nesse contexto, em contraponto à Justiça Comum e ao direito (civil) individual, como mais adequados ao tratamento desses conflitos.

A incorporação da Justiça do Trabalho no Poder Judiciário pela Constituição de 1946 não representou apenas uma modificação formal - a indicar que os magistrados trabalhistas passariam a ser "juízes" como os demais -, ou a mera positivação de seu caráter jurisdicional - na linha do que já havia decidido anteriormente o Supremo Tribunal Federal. Consistiu, mais do que isso, no amplo reconhecimento da função da Justiça do Trabalho e do direito do trabalho como instrumentos essenciais de atuação na ordem econômico-social, de maneira a garantir a solução dos conflitos entre empregados e empregadores.

A alteração promovida pela Constituição de 1946 é, portanto, fundamental para se compreender a consolidação da Justiça do Trabalho e do direito do trabalho no país. Sua análise fornece elementos para se empreender um exame crítico da atuação posterior dessa Justiça Especial e da aplicação por ela feita do direito do trabalho. Uma pergunta a ser colocada, a partir do que foi aqui investigado, é a de como a Justiça do Trabalho, utilizando o ramo do direito que lhe é próprio e no exercício de sua competência, inclusive a normativa, vem realizando a função de conferir um tratamento adequado aos conflitos sociais. ${ }^{27}$ Essa é uma questão relevante, atual e ainda a ser aprofundada.

\title{
IDEAS AND SPEECHES ABOUT LABOUR JUSTICE IN BRAZIL: ITS INCLUSION IN THE JUDICIARY POWER EXAMINED FROM THE CONSTITUENT ASSEMBLY OF 1946
}

\begin{abstract}
The implementation in Brazil of a Labour Justice with corporative feature was fought by liberal strands, but defended by supporters of Getúlio Vargas' state authoritarianism. This opposition of ideas becomes evident in the
\end{abstract}

\footnotetext{
${ }^{27}$ É possível pensar, por exemplo, nas diversas críticas dirigidas à competência normativa e a seu uso pela Justiça do Trabalho (SILVA, 2008 e AUTOR, 2014).
} 
debate between Oliveira Viana and Waldemar Ferreira, at the second half of the 1930s. This article's purpose is to investigate this stage of the process of consolidation of Labour Justice, which will culminate in its inclusion in the Judiciary Power. To that objective, in a first moment, is analysed the debate between Oliveira Viana and Waldemar Ferreira about Labour Justice and its competence, in particular the normative. Then, from the Legislative Power Diaries, are examined the speeches in the Constituent Assembly of 1946 relative to Labour Justice and its incorporation in the Judiciary Power. The results of the research indicate that the liberal opposition gave way to the recognition of the function of Labour Justice and labour law as necessary instruments to deal with conflicts between employees and employers. This finding leads to the inquiry, for future studies, on how Labour Justice has been effectively performing this function.

Keywords: History of law. Labour Justice. Oliveira Viana. Constituent Assembly of 1946. 1946 Constitution.

\section{REFERÊNCIAS BIBLIOGRÁFICAS}

BALEEIRO, Aliomar. "A Constituinte e a Constituição Federal de 1946". In: BALEEIRO, Aliomar e SOBRINHO, Barbosa Lima. Constituições Brasileiras: 1946. Brasília: Senado Federal e Ministério da Ciência e Tecnologia, Centro de Estudos Estratégicos, 2001, pp. 13/31

BERCOVICI, Gilberto. "Tentativa de instituição da democracia de massas no Brasil: instabilidade constitucional e direitos sociais na Era Vargas (1930-1964)”. In: FONSECA, Ricardo Marcelo e SEELAENDER, Airton (orgs.). História do direito em perspectiva. 1ª Ed., 4a Reimpr. Curitiba: Juruá, 2012, pp. 375-414

BIAVASCHI, Magda Barros. O Direito do Trabalho no Brasil - 1930/1942: a construção do sujeito de direitos trabalhistas. Tese de Doutorado. Instituto de Economia, Universidade Estadual de Campinas, Campinas, 2005.

BOITO JR, Armando. O sindicalismo de Estado no Brasil - uma análise crítica da estrutura sindical. Campinas: Editora da Unicamp, São Paulo: Hucitec, 1991

BOITO JR, Armando. "Neoliberalismo e corporativismo de Estado no Brasil". In: ARAÚJO, Angela Maria Carneiro (Org.). Do corporativismo ao neoliberalismo - Estado e trabalhadores no Brasil e na Inglaterra. 
São Paulo: Boitempo Editorial, 2002

BONAVIDES, Paulo e ANDRADE, Paes de. História Constitucional do Brasil. $8^{a}$ ed. Brasília: OAB Editora, 2006;

BRAGA, Sérgio Soares. Quem foi quem na Assembléia Nacional Constituinte de 1946: um perfil socioeconômico e regional da Constituinte de 1946. Brasília: Câmara dos Deputados, Coordenação de Publicações, 1998

BRASIL JR., Antônio da Silveira. "Intelectuais e statemakers: Oliveira Vianna, Evaristo de Moraes Filho e a ação coletiva no Brasil”. In: Estudos Históricos, Rio de Janeiro, vol. 23, nº 46, p. 301-320, julho-dezembro de 2010

BRASIL. Diário do Poder Legislativo. Ano I, no 3, Rio de Janeiro, 6 de fevereiro de 1946 (sessão solene de instalação da Assembleia Constituinte) (a)

Diário do Poder Legislativo. Comissão da Constituição. Ano I, no 28, Rio de Janeiro, 16 de março de 1946 (b)

Diário do Poder Legislativo. Quinta Subcomissão da Constituição, Ano I, no 32, Rio de Janeiro, 22 de março de 1946 (c)

Diário do Poder Legislativo, Comissão da Constituição. Ano I, nº 53, Rio de Janeiro, 26 de abril de $1946(d)$

Diário do Poder Legislativo, Comissão da Constituição. Ano I, n 54, Rio de Janeiro, 27 de abril de $1946(\mathrm{e})$

Diário do Poder Legislativo, Comissão da Constituição. Ano I, no 56, Rio de Janeiro, 2 de maio de 1946 (f)

Poder Executivo. "Exposição de Motivos". Decreto n²2.132, de 25 de novembro de 1932. Rio de Janeiro, DF, 23.11.1932. Disponível em http://www2.camara.leg.br/legin/fed/decret/1930-1939/decreto22132-25-novembro-1932-526777-exposicaodemotivos-pe.pdf (acesso em 22.8.2015)

Constituição (1934). Constituição da República dos Estados Unidos do Brasil. Diário Oficial da União, Rio de Janeiro, 16.7.1934

Constituição (1937). Constituição dos Estados Unidos do Brasil. Diário Oficial da União, Rio de Janeiro, 10.11 .1937

Constituição (1946). Constituição dos Estados Unidos do Brasil. Diário Oficial da União, Rio de Janeiro, 19.9.1946 
Supremo Tribunal Federal. Recurso Extraordinário no 6.310, Distrito Federal, Rel. Min. Goulart de Oliveira. Julgado em 13 de julho de 1943, Coletânea de Acórdãos n² 230, p. 149. Distrito Federal, s/d.

CARVALHO, José Murilo de. "A utopia de Oliveira Viana”. In: Estudos históricos, Rio de Janeiro, vol. 4, nº 7 , 1991, p. $82-99$

COSTA, Pietro. "Passado: dilemas e instrumentos da historiografia". In: Revista da Faculdade de Direito UFPR, Curitiba, n. 47, p. 21-28, 2008

DELGADO, Maurício Godinho. Curso de Direito do Trabalho. 13a Ed. São Paulo: LTr, 2014

FAUSTO, Boris. O pensamento nacionalista autoritário (1920-1940). Rio de Janeiro: Jorge Zahar Editor, 2001

FERREIRA, Waldemar Martins. Princípios de Legislação Social e Direito Judiciário do Trabalho. Vol. I. São Paulo: Editora Limitada, 1938

GOMES, Angela de Castro. "Retrato falado: a Justiça do Trabalho na visão de seus magistrados". In: Estudos Históricos, Rio de Janeiro, nº 37, janeiro-junho de 2006, p. 55-80

HESPANHA, Antonio Manuel. Cultura Jurídica Européia - Síntese de um Milênio. Florianópolis: Fundação Boiteux, 2005

KOERNER, Andrei. "A História do Direito como recurso e objetivo de pesquisa”. In: Diálogos (Maringá. Online), v. 16, n. 2, p. 627-662, mai-ago./2012

MIRANDA, Pontes de. Comentários à Constituição de 1946. $4^{a}$ Ed. Tomo III (Arts. 73 - 128). Rio de Janeiro: Borsoi, 1963

MOREL, Regina Lucia M. e PESSANHA, Elina G. da Fonte. "A justiça do trabalho". In: Tempo Social, v. 19, n. 2, p. 87-109, novembro de 2007 
PORTAL DA FUNDAÇÃO GETÚLIO VARGAS. CENTRO DE PESQUISA E DOCUMENTAÇÃO DE HISTÓRIA CONTEMPORÂNEA DO BRASIL. Verbete biográfico. Valdemar Martins Ferreira. Rio de Janeiro, s/d. Disponível em http:/ /www.fgv.br/cpdoc/acervo/dicionarios/verbete-biografico/valdemar-martinsferreira (acesso em 20.1.2018).

SANTOS, Rogerio Dultra dos. "Oliveira Vianna e o Constitucionalismo no Estado Novo: corporativismo e representação política”. In: Sequência, n. 61, p. 273-307, dez. 2010

SANTOS, Wanderley Guilherme. Ordem Burguesa e Liberalismo Político. São Paulo: Duas Cidades, 1978

SARASOLA, Ignacio Fernández. "La historia constitucional: método e historiografía a la luz de um bicentenario Hispánico”. In: FHI -Forum historiae iuris, n.11, jun. 2009

SCHIAVI, Mauro. Manual de Direito Processual do Trabalho. 10 Ed. São Paulo: LTr, 2017

SEVERO, Valdete Souto. “O fim da Justiça do Trabalho". In: Justificando, 18.10.2017, acesso em 20.1.2018 (http://justificando.cartacapital.com.br/2017/10/18/o-fim-da-justica-do-trabalho/)

SILVA, Sayonara Grillo Coutinho Leonardo de. Relações coletivas de trabalho. São Paulo: LTr, 2008

SKIDMORE, Thomas. Brasil: de Getúlio a Castelo (1930-1964). Trad. De Ismênia Tunes Dantas. 14a Ed. Rio de Janeiro: Paz e Terra, 2007

SOBRINHO, Barbosa Lima. "O Direito Eleitoral e a Constituição de 1946". In: BALEEIRO, Aliomar e SOBRINHO, Barbosa Lima. Constituições Brasileiras: 1946. Brasília: Senado Federal e Ministério da Ciência e Tecnologia, Centro de Estudos Estratégicos, 2001, pp. 33/53

STRECK, Lênio Luiz. "E a grande ideia é... extinguir a Justiça do Trabalho! Peça em 10 atos". In: Conjur, 17.8.2017, acesso em 20.1.2018 (https://www.conjur.com.br/2017-ago-17/senso-incomum-grande-ideiaextinguir-justica-trabalho)

SUANZES-CARPEGNA, Joaquín Varela. “Algumas reflexões metodológicas sobre a história constitucional”. In: 
RIHGB, a. 169 (440):09-28, jul/set, 2008

VIANA, Oliveira. "Anteprojeto de Organização da Justiça do Trabalho, Apresentado à Câmara dos Deputados pelo Presidente da República em 1937”. In: Problemas de Direito Corporativo. 2a Ed. Brasília: Câmara dos Deputados, 1983 (a)

VIANA, Oliveira. Problemas de Direito Corporativo. 2a Ed. Brasília: Câmara dos Deputados, 1983 (b)

VIANA, Oliveira. "Notas à margem do parecer do Professor Waldemar Ferreira". In: Problemas de Direito Corporativo. 2a Ed. Brasília: Câmara dos Deputados, 1983 (c)

VIANA, Oliveira. Populações Meridionais do Brasil. Brasília: Senado Federal, 2005

VIANNA, Luiz Werneck. Liberalismo e sindicato no Brasil. 3a ed. Rio de Janeiro: Paz e Terra, 1989

WEFFORT, Francisco C. Formação do pensamento político brasileiro - ideias e personagens. São Paulo: Ática, 2006.

Trabalho enviado em 09 de março de 2018

Aceito em 10 de junho de 2018 